SHORT REPORT

\title{
Prognosis of conservatively treated patients with Pott's paraplegia: logistic regression analysis
}

\author{
J Kalita, U K Misra, S K Mandal, M Srivastava
}

J Neurol Neurosurg Psychiatry 2005;76:866-868. doi: 10.1136/jnnp.2004.037051

Objective: To evaluate the prognostic significance of various clinical, radiological, and neurophysiological findings in conservatively treated patients with Pott's paraplegia, using multiple regression analysis.

Methods: The study included 43 patients with Pott's paraplegia, managed conservatively. The diagnosis of Pott's spine was based on clinical, magnetic resonance imaging, and computed tomography or ultrasound guided aspiration biopsy. All patients were examined clinically, and motor evoked potentials (MEPs) to lower limbs and tibial somatosensory evoked potentials (SEP) were recorded. Outcome at six months was defined as good or poor. For evaluating predictors of outcome, 15 clinical, investigative, and evoked potential variables were analysed, using multiple logistic regression analysis.

Results: The age range of the patients was 16-70 years, and 22 were female. Mild spasticity with hyperreflexia only was seen in 13 patients. In the remaining, weakness was severe in eight, and moderate and mild in 11 patients each. Twenty patients had loss of joint position sensation. MEP and SEP were abnormal in 19 and 18 patients, respectively. On multiple regression analysis, the best model predicting six month outcome included power, paraplegia score, SEP, and MEP.

Conclusion: Patients with Pott's paraplegia are likely to recover completely by six months if they have mild weakness, lower paraplegia score and normal SEPs and MEPs.

S pinal tuberculosis is the commonest form of bone and joint tuberculosis in developing countries and constitutes $1 \%$ of all tuberculosis. ${ }^{12}$ There has been a resurgence of tuberculosis in the developed world because of acquired immune deficiency syndrome, organ transplantation, immunosuppression, and immigration. It has thus become a more important problemnow thanitwasin therecent past.

Modern pharmacotherapy and imaging have changed the outlook of neurotuberculosis. With computed tomography (CT) scanning and magnetic resonance imaging (MRI), it is now possible to diagnose spinal tuberculosis at an early stage, differentiate it from other diseases, and objectively monitor the progress. ${ }^{3-5}$ In addition, sensory and motor evoked potentials provide a means of objectively documenting sensorimotor dysfunction.

Several clinical predictors of spinal tuberculosis have been evaluated but none has been found to be useful. ${ }^{6}$ Poor prognosis has been reported in patients with disseminated tuberculosis, paraplegia, and secondary infection of sinuses. ${ }^{7}$ Most of the earlier studies, however, did not employ modern chemotherapeutic regimens, MRI, and evoked potential studies. ${ }^{6-9}$ In the present communication we report the role of various clinical, MRI, and evoked potential changes in predicting the six month outcome of conservatively treated patients with Pott's paraplegia.

\section{PATIENTS AND METHODS}

Our prospective study included consecutive patients with Pott's spine and varying degree of neurological deficits, treated conservatively during 1993-2003. The diagnosis of Pott's spine was based on clinical findings, MRI, and CT or ultrasound guided aspiration biopsy. Of 45 patients recruited, 43 completed the six months follow up and were included in the present study. We took a thorough history and the patients underwent detailed clinical evaluation. Muscle power was tested on a 0-5 MRC (Medical Research Council) scale. We tested tone, reflex and sensations of pinprick, joint position, and vibration, and noted presence of bone deformity and tenderness, soft tissue swelling, and extraspinal tuberculosis. The following investigations were done: blood count, erythrocyte sedimentation rate (ESR), serum chemistry, venereal disease research laboratory (VDRL) test, human immunodeficiency virus (HIV) serology, and radiographs of the chest and spine. Spinal MRI was performed using $2 \mathrm{~T}$ scanner operating at $1.5 \mathrm{~T}$, and $\mathrm{T} 1, \mathrm{~T} 2$, $\mathrm{PD}$, and $\mathrm{Tl}$ contrast images were obtained.

We recorded tibial sensory evoked potentials (SEPs) bilaterally from $\mathrm{Cz}$ and $\mathrm{Ll}$ after stimulating the tibial nerve at the ankle. The central sensory conduction time (CSCT) was calculated by subtracting lumbar latency from the cortical. The electrical stimulator (Digitimer D180, Herts, England) was used for motor evoked potentials (MEPs) of the lower limb. The cortical stimulation was given at the vertex and the spinal stimulation at the twelfth thoracic vertebra. MEPs were recorded from the tibialis anterior (TA) by surface electrodes. Central motor conduction time to TA (CMCT-TA) was calculated by subtracting spinal latency from the cortical. We considered the evoked potentials abnormal if the cortical potentials were unrecordable or CMCT and CSCT values exceeded mean $+2.5 \mathrm{SD}$ of controls. In our laboratory, the upper limit of CMCT-TA was $16.1(12.1+1.6) \mathrm{ms}$ and tibial CSCT $22.2(17.56+1.9) \mathrm{ms}^{10}$ Patients were treated with rifampicin, isoniazid, pyrazinamide, and ethambutol and advised rest for three months. Outcome at six months was defined as poor (bedridden or dependent for activities of daily living) or good (independent for activities of daily living). ${ }^{11}$

\section{Statistical analysis}

The independent variables possibly related to outcome were categorised as follows:

- Sex: male $=1$, female $=2$

- Power: grade $0-1=1$, grades $2-3=2$, grades $>3=3$

Abbreviations: CMCT-TA, central motor conduction time to TA; CSCT, central sensory conduction time; MEP, motor evoked potential; SEP, sensory evoked potential; TA, tibialis anterior 


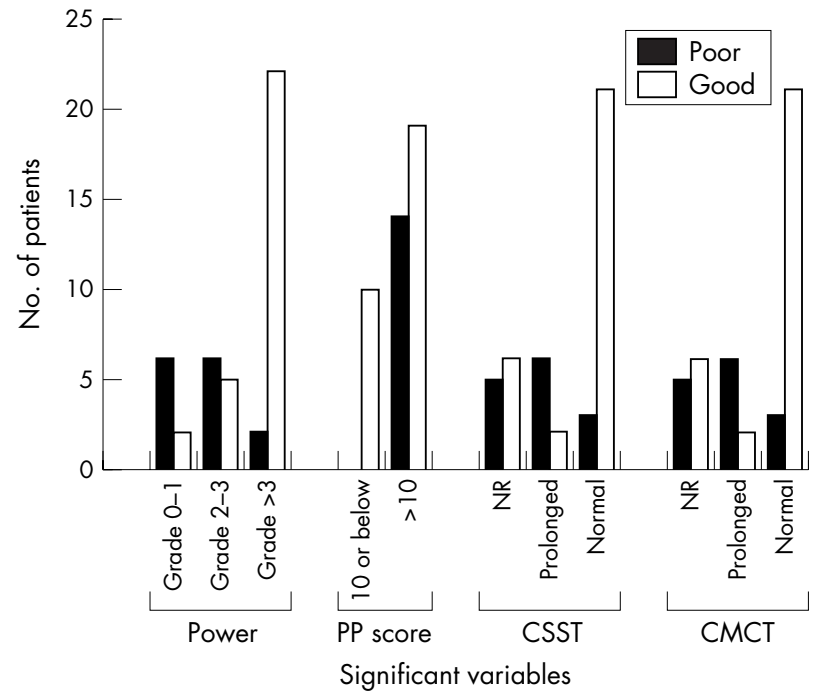

Figure 1 Relation between prognostic predictors of Pott's paraplegia and six month outcome on multiple regression analysis. CMCT, central motor conduction time; CSCT, central sensory conduction time; NR, not recordable; PP, paraplegia score.

- Tone: reduced $=1$, increased $=2$, normal $=3$

- Reflex: reduced $=1$, increased $=2$, normal $=3$

- Sensory loss: present $=1$, absent $=2$

- Vertebral level: cervical $=1$, dorsal $=2$, lumbar $=3$

- Number of vertebrae involved: $>2=1, \leqslant 2=2$

- Paravertebral abscess and deformity: present $=1$, absent $=2$

- CMCT and CSCT: not recordable $=1$, prolonged $=2$, normal $=3$

Raw scores of age, duration, paraplegia score ${ }^{12}$ and ESR were included. The paraplegia score was obtained using a scale that included assessment of ambulation, ability to work in the field, ability to squat, urinary dysfunction and change in occupation due to illness. The minimum score on this scale is 5 and maximum 18. The higher the score the greater the functional disability. ${ }^{12}$ The dichotomous dependent variable was assigned the value of 1 if the outcome was good and 0 if it was poor. We initially undertook a univariate logistic regression analysis, and then we used the variables having significance $<0.4$ for multiple regression analysis. The best set of variables predicting outcome was obtained by stepwise multiple logistic regression analysis. ${ }^{13}$

\section{RESULTS}

Our results are based on 43 patients with Pott's paraplegia (22 females, 21 males; mean age 42.1 years, range 16-70) all of whom had backache (mean duration 8.2 months, range $0.7-36)$.
A total of 13 patients had fever and five were quadriplegic. Weakness was severe (grade $0-1$ ) in eight patients and moderate (grades 2-3) and mild (grades $>3$ ) in 11 patients each. Power was normal in 13 patients, but they had spasticity with hyperreflexia suggesting pyramidal dysfunction. The lower limbs were spastic in 27 patients and hypotonic in one patient. In 32 patients, the tendon reflexes were exaggerated, and they were reduced in four patients and normal in seven. Loss of joint position sensations was noted in 20 patients. Sensation of pinprick was reduced in 18 patients (level: dorsal $=12$, cervical $=2$, lumbar $=4$ ) and gibbus was present in 17 patients.

On MRI, a single vertebra was involved in five patients, two vertebrae in 27 and three verterbrae in 11 patients. Soft tissue shadow was present in 35 and spinal cord compression in 30 patients. Four patients had associated pulmonary and two had associated lymph node tuberculosis. CMCT-TA was not recordable in 11 and was prolonged in eight patients. SEP was not recordable in 16 and CSCT was prolonged in two patients. At six months, 29 patients had good and 14 poor recovery.

On logistic regression analysis with each prognostic variable separately, power $(Z=+3.30)$, tone $(Z=+2.37)$, sensory loss $(Z=+2.70)$, level of vertebral involvement $(Z=-2.30)$, CMCT $(Z=+2.29)$, CSCT $(Z=+3.13)$ and ESR $(Z=-2.26)$ were significantly related to outcome. On multiple logistic regression analysis, the best model predicting six month outcome included power, paraplegia score, CMCT and CSCT (table 1). Figure 1 shows the relation of these variables with outcome.

\section{DISCUSSION}

In the present study, the six month outcome of Pott's paraplegia was best predicted by power, paraplegia score, CMCT, and CSCT (as evaluated by multiple regression analysis). Most of our patients with mild weakness recovered completely (22/24 (91.7\%)) as opposed to only $25 \%(2 / 8)$ with severe weakness. In Pott's paraplegia, the pathology begins in the anterior portion of the body of the vertebra, and, later, involvement of the adjacent vertebrae may result in wedge collapse. ${ }^{4}$ Inflammation, oedema, and necrosis may result in abscess formation, which in turn may result in spinal cord compression and focal demyelination of the ascending and descending tracts. Therefore, because of its anterolateral location, the corticospinal tract is likely to be affected more commonly and relatively early in the disease resulting in weakness. Moreover, activities of daily living and paraplegia score are mainly dependent on power. Regression of oedema, abscess, and focal demyelination following antitubercular treatment may manifest as clinical recovery, and may be more complete than bony destruction. In the present study, $71.4 \%(25 / 35)$ of patients with paraspinal abscess had "good" recovery as opposed to 50\% (4/8) without abscesses.

Tibial CSCT and CMCT-TA were helpful not only in objectively documenting the respective deficit but also in

\begin{tabular}{|c|c|c|c|c|c|}
\hline Variable & Coefficient & $\begin{array}{l}\text { Standard } \\
\text { error }\end{array}$ & $\begin{array}{l}\text { Odds } \\
\text { ratio }\end{array}$ & $\begin{array}{l}95 \% \text { Confidence } \\
\text { limits }\end{array}$ & $p$ value \\
\hline Power & 2.234 & 0.876 & 9.342 & 1.678 to 52.006 & 0.011 \\
\hline Paraplegia score & 3.101 & 1.491 & 22.211 & 1.194 to 413.097 & 0.038 \\
\hline Central motor conduction time & -2.929 & 1.500 & 0.053 & 0.003 to 1.010 & 0.051 \\
\hline Central sensory conduction time & 2.797 & 1.238 & 16.374 & 1.446 to 185.371 & 0.023 \\
\hline Constant & -9.276 & 3.487 & & & 0.008 \\
\hline
\end{tabular}


predicting outcome. Of the patients with normal CSCT, $87.5 \%$ (21/24) recovered, whereas only $42.1 \%$ (8/19) with abnormal SEP recovered. SEP abnormality suggests involvement of the posterior column and perhaps indicates a more extensive involvement because most tubercular infections begin anteriorly. ${ }^{4}$ All our patients had motor signs and symptoms, but only 20 had sensory deficits. The high frequency of CMCT abnormalities may be due to the larger diameter and anterolateral location of the corticospinal tract, which make it relatively more vulnerable in the early stage of Pott's spine.

We did not come across any study in the available literature evaluating the prognostic value of MEPs and SEPs in Pott's paraplegia with multivariate analysis. In a previous study on seven patients with Pott's paraplegia SEP abnormalities were present in four patients and were associated with poor outcome. ${ }^{3}$ The prognostic role of MEP and SEP has been reported in various other spinal cord diseases such as transverse myelitis, cervical spondylosis, and subacute combined degeneration. ${ }^{14-16}$ An MRC study of Pott's spine using 21 clinical and radiological variables failed to detect any prognostic predictor. ${ }^{8}$ The role of surgery in Pott's spine is still controversial. ${ }^{17-19}$ A recent study from the USA recommended decompression and stabilisation in Pott's spine with neurological symptoms and signs. Most of the patients in that study improved although two died. ${ }^{5}$ In our study, none of the patients underwent surgery, 67.4\% (29/43) showed full recovery at six months, and there were no deaths.

We conclude that patients with Pott's paraplegia with mild weakness, lower paraplegia score and normal SEP and MEP are likely to recover fully after six months of conservative treatment.

\section{ACKNOWLEDGEMENT}

We thank R K Nigam for technical help.

\author{
Authors' affiliations \\ J Kalita, U K Misra, Department of Neurology, Sanjay Gandhi Post \\ Graduate Institute of Medical Sciences, Lucknow, India \\ S K Mandal, M Srivastava, Department of Biostatistics, Central Drug \\ Research Institute, Lucknow, India \\ Competing interests: none declared
}

Correspondence to: Prof U K Misra, Department of Neurology, Sanjay Gandhi Post Graduate Institute of Medical Sciences, Raebareily Road, Lucknow-226014, India; ukmisra@sgpgi.ac.in; ukmisra@ indiatimes.com

Received 18 January 2004

Revised version received 2 September 2004

Accepted 20 September 2004

\section{REFERENCES}

1 Grose GJ, Pais MJ, Kusske JA, et al. Tuberculosis spondylitis. A report of 6 cases and a review of the literature. Medicine 1983:62:178-93,

2 Davidson PT, Horowitz I. Skeletal tuberculosis. Am J Med 1970;48:72-84.

3 Misra UK, Kalita J. Somatosensory and motor evoked potentials in patients with Pott's paraplegia. Paraplegia 1996;34:272-6.

4 Shridhar K. Tuberculosis of the spine. In: Ramamurthi B, Tandon PN, eds. Text book of Neurosurgery Vol I. 2nd edn. New Delhi: BI Churchill Livingstone, 1996:496-513.

5 Rezai AR, Lee M, Cooper PR, et al. Modern management of spinal tuberculosis. Neurosurgery 1995;36:87-98.

6 Medical Research Council working party on tuberculosis of the spine. A comparison of 6 or 9-month course regime of chemotherapy in patients receiving ambulatory treatment or undergoing radical surgery for tuberculosis of the spine. Ind J Tuberc 1989;36:1-21.

7 Lancashire JD. Tuberculosis of the spine: An analysis of the results of conservative treatment and of the factors influencing the prognosis. J Bone Joint Surg 1951;33:517-31.

8 Konstam PG, Blesovsky A. The ambulant treatment of spinal tuberculosis. Br J Surg 1962;50:26-37.

9 Tuli SM. Results of treatment of spinal tuberculosis by "Middle-path" regime. J Bone Joint Surg 1975;57:13-23.

10 Misra UK, Kalita J. Clinical Neurophysiology. New Delhi: Elsevier India, 2004.

11 Misra UK, Kalita J, Kumar S, et al. Radiological and neurophysiological changes in Japanese encephalitis. J Neurol Neurosurg Psychiatry 1994;57:1484-7.

12 Misra UK, Sharma VP, Singh VP. Clinical aspects of neurolathyrism in Unnao, India. Paraplegia 1993;31:249-54.

13 McGee DL. A programme logistic regression on IBM PC. Am J Epidemiol 1986; 124:702-95.

14 Kalita J, Misra UK, Mandal SK. Prognostic predictors of acute transverse myelitis. Acta Neurol Scand 1998;98:60-3.

15 Misra UK, Kalita J. Motor evoked potential is useful for monitoring the effect of Collar therapy in cervical spondylotic myelopathy. J Neurol Sci 1998; 154:222-8

16 Misra UK, Kalita J, Das A. Vitamin B12 deficiency neurological syndromes: A clinical, MRI and electrodiagnostic study. Electromyogr Clin Neurophysiol 2003:43:57-64.

17 Moon MS, Ha KY, Sun DH, et al. Pott's paraplegia-67 cases. Clin Orthop 1996;323:122-8.

18 Moula T, Fonles JV, Kassab MT, et al. Pott's paraplegia: A clinical review of operative and conservative treatment in 63 adults and children. Int Orthop 1981;5:23-9.

19 Turgent M. Spinal tuberculosis (Pott's disease): Its clinical presentation, surgical management and outcome. A survey study on 694 patients. Neurosurg Rev $2001 ; 24: 8-13$. 